\title{
Condom use: a less travelled route among minibus taxi drivers and their taxi queens in KwaZulu-Natal, South Africa
}

\author{
Gugu G Mchunu, Joanne R Naidoo², Busisiwe P Ncama
}

\author{
1. School of Nursing and Public Health, University of Kwazulu-Natal, South Africa. \\ 2. Department of Nursing Sciences, Nelson Mandela University. \\ 3. College of Health Sciences, University of KwaZulu-Natal.
}

\begin{abstract}
Background: Despite significant gains in the HIV epidemic in South Africa, with reduction in mortality and elimination of vertical transmission, national HIV prevalence remains high, with women rather than men continuing to bear higher burden of the disease. Population subgroups, through ignorance, disbelief or recklessness, continue to engage in risky sexual behaviour. A substantial proportion of minibus taxi drivers engage in risky sex, seldom seeing themselves at risk for STIs or HIV/AIDS. These taxi drivers have been linked with so-called taxi queens, with whom they engage in transactional and intergenerational relationships.

Objectives: The study explored condom use and condom negotiation strategies among taxi drivers and taxi queens in KwaZulu-Natal, South Africa.

Methods: Applying explorative qualitative design, we conducted focus group discussion and individual interviews among participants who were purposively recruited in KwaZulu-Natal.

Results: Qualitative data analysis revealed that condom use and negotiation are sources of conflict for the participants. In addition, the strategies employed by participants to ensure condom usage are not always sustainable and are likely to be problematic due to a variety of complex factors.

Conclusion: Our study concludes by recommending a nested public health response that takes cognizance of factors that promote sustainable condom use strategies among this population subgroup.

Keywords: Condom use, minibus taxi drivers, KwaZulu-Natal, South Africa.

DOI: https://doi.org/10.4314/ahs.v20i2.15

Cite as: Mchunu GG, Naidoo JR, Ncama BP. Condom use: a less travelled route among minibus taxi drivers and their taxi queens in KwaZulu-Natal, South Africa. Afri Health Sci. 2020; 20(2): 658-665. https:/ / doi.org/10.4314/ahs.v20i2.15
\end{abstract}

\section{Background}

Recent literature has shown that women in Africa, especially young women, are at particularly high risk of contracting HIV. ${ }^{1}$ This risk is attributed not only to behavioural factors but also to elevated genital concentrations of HIV target-cell-recruiting chemokines and a genital inflammatory profile that increases the risk of HIV acquisition among African women. ${ }^{2}$ This demonstrates that consistent condom use remains the most effective strategy currently available for the prevention of HIV and sexually transmitted infections (STIs), and has been

\section{Corresponding author: \\ Gugu G Mchunu, \\ School of Nursing and Public Health, University of Kwazulu-Natal, South Africa. \\ $5^{\text {th }}$ Floor, Desmond Clarence Building, Howard College Campus, University of Kwazulu-Natal, Durban. 4041. \\ Email: mchunug@ukzn.ac.za}

documented as providing a $99 \%$ level of protection if used correctly and consistently. ${ }^{3}$

Cultural norms and gender inequality are noted as consistent determinants in risk of HIV for women. ${ }^{4}$ Despite the threat posed by the rapid spread of HIV, many subgroups of the population continue to engage in risky sexual behaviour, possibly due to ignorance, disbelief or recklessness. ${ }^{5}$ Minibus taxi drivers belong to an occupation in which the prevailing lifestyle has been identified as making them highly susceptible while on duty because they travel throughout the city, encounter many different people, receive money, and sometimes find themselves pursued by women who hope to have money spent on them by the drivers. ${ }^{6}$

Relevant research findings have indicated that a substantial proportion of minibus taxi drivers engage in risky sex but seldom considered themselves to be at risk of STIs or HIV/AIDS. ${ }^{6,7,8}$ With such risky sexual behaviours, links have been made between minibus taxi 
drivers' sexual relationship and so-called taxi queens, whereby young and impoverished women engage in transactional and intergenerational relationships. ${ }^{9,10}$ HIV transmission has been linked in particular to concurrent relationships and intergenerational sex (age mixing in sex). ${ }^{11}$

Gender norms can create and reinforce unequal positioning in relationships for women, resulting in an inability to negotiate condom use. For men, gender norms can exacerbate concepts of masculinity and promote sexual prowess and male control over women. ${ }^{12}$ Moreover, men and women alike have been reluctant to use male condoms with their primary sexual partners partly because it reduces intimacy, but also because condoms intrude in the relationship by disrupting the possibility of having children; condoms have thus been seen by both men and women as a barrier to sexual pleasure and as limiting the 'naturalness' of sex..$^{13}$

Having the confidence to negotiate safer sex practices still remains a crucial tool in seeking to ensure condom use. It is not yet clear, however, how effective condom negotiation is, especially in these transactional relationships. ${ }^{14}$ For example, women may put higher priority on relationship maintenance than on self-protective behaviour, and may end up not insisting on using condoms to avoid jeopardizing their relationships. ${ }^{15}$ Condom use has always been seen as a challenge for women in such relationships, with women attesting how men control their bodies either through physical or emotional violence or through economic power. ${ }^{13}$

\section{Purpose of the study}

The purpose of this study was to explore the experiences of condom use and negotiation strategies among minibus taxi drivers and the taxi queens.

\section{Objectives}

The objectives of the study were to explore:

- $\quad$ experiences of condom use among minibus taxi drivers and taxi queens

- $\quad$ strategies for negotiation of condom use among minibus taxi drivers and taxi queens

\section{Definitions of key concepts}

Minibus taxi: Considered one of the most popular mode of public transport in South Africa. The vehicle often carries 15 to 20 passengers. It conveys passengers on a fixed or semi-fixed route without a timetable and departs when all seats are filled. It may stop anywhere to pick up or drop off passengers.
Minibus taxi driver: A person who drives a minibus taxi Minibus taxi rank: A designated area, usually in the city or township; where the minibus taxis wait for commuters to board them. Taxi operators (owners), rank managers, taxi drivers and taxi marshals (the person who maintains order among the commuters awaiting the minibus taxi) are usually present at taxi ranks. It is usually a very busy place, with both formal and informal traders in close proximity. Informal trade can include hair salons, mechanics, food traders and traders in traditional herbal medication.

Taxi queen: In South Africa, taxi queen refers to a woman, often young, who is in a casual sexual relationship with a minibus taxi driver.

\section{Methodology}

This article reports on findings from a larger threephase study that used a mixed methodology design. The findings of the earlier phases have been reported in previous publications. ${ }^{7,8}$ This article reports on the qualitative section of the study, which was gathered over the period of 2013 to 2015. The aim of the qualitative section of the main study was to explore condom use and strategies that inform condom use negotiations among the minibus taxi drivers' and the taxi queens. Utilizing qualitative methods in this phase was appropriate in order to capture the personal perspectives and experiences of minibus taxi drivers' and taxi queens. ${ }^{16}$

\section{Research design and data collection}

An exploratory qualitative design was used in this study as being appropriate for exploring experiences and strategies related to condom use17 and because the sample was small and non-representative. Due to the study using two types of participants, that being the taxi drivers and the taxi queens, data was gathered for both types of participants separately. For the taxi drivers, the use of two focus group discussions (FGDs) were conducted among the minibus taxi drivers. The researchers were first introduced by identified taxi owners to the taxi rank managers and to the taxi drivers present at the taxi rank. The researchers had been told to visit the rank during the 'quiet time', which was normally between 9 a.m. and 12 a.m. During this time the driv-ers would be sitting in groups talking or playing games while waiting for their passengers. The researchers then asked the drivers if they would be interested in partici-pating in the study and initiated the FGDs. Each focus group consisted of 8 to 10 taxi drivers and the discus-sions were conducted either inside a stationary taxi or in a private sitting area. There was thus a total of 18 taxi 
drivers who participated in the two FGDs. Each of the focus group lasted for about 45 minutes to 1 hour. To explore the experiences of the taxi queens, an in- depth individual semi-structured interview technique was used. Sampling the taxi queens was through net- work sampling, as the taxi queens were not easily iden- tifiable. The first taxi queen was introduced to the re- searchers through her taxi-driver partner, following the data gathering with the first taxi queen she referred researchers to her friend who was also a taxi queen. This process of network sampling continued, until a saturated sample of six taxi queens was interviewed. Both forms of data gathering, namely the focus group discussion with the taxi drivers and the in-depth individual semi structured interviews with the taxi queens enabled the researchers to gather a range of perspectives regarding the expe-rience of condom use and condom negotiation. The FGDs used as a data collection method in this study, were just one aspect of a broader on-going research project which utilized mixed methods. To encourage participants to talk freely during the discussion, the focus groups were homogenous and the discussions were conducted in the participants' home language, isiZulu. Interviews were audio recorded and all transcripts were translated from isiZulu to English and back translated from English to isiZulu. This process was verified by an isiZulu expert who ensured the veracity of the transla-tion and that all nuances remained as true to the spoken language of isiZulu that the interviews were conducted in.

\section{Population, sampling and setting}

The study was conducted in the KwaZulu-Natal province, which is one of nine provinces in South Africa. The KwaZulu- Natal province is further divided into eleven health districts or municipalities, eThekwini, which is largely urbanised, is also considered one of the most populated municipalities in KwaZulu-Natal. There is thus a higher commute of transport from eThekwini to other municipalities through the use of mini-bus mode of transport. The targeted population for this study were minibus taxi drivers and taxi queens. Since this industry is widely considered unsafe for outsiders, the researchers had to undertake planned community entry in order to gain the trust of the participants. Key informants were identified through a snowballing technique, and issues of community entry were given careful consideration. The key informants included rank managers, taxi association managers and taxi owners. The researchers were introduced first to the taxi associations and taxi rank managers by identified taxi owners, who then introduced the researchers to those taxi drivers who were at the taxi rank at the time of data collection. All key informants in the desired setting were purposively sampled in order to point researchers in the right direction and also so that they could introduce researchers to the minibus taxi drivers. The sites comprised various taxi ranks within the eThekwini municipality and were purposely selected based on their accessibility. Purposive sampling was done to recruit taxi driver participants, based on their availability and willingness to participate in the study. The taxi queens were recruited through sno sampling: one of the taxi drivers referred the researchers to his girlfriend who was willing to participate in the study. Following the interview, the girlfriend referred the researchers to her acquaintance who was also a taxi queen. The taxi queens were usually working within the taxi rank as informal traders such as food hawkers, hairdressers or just hanging around the taxi rank.

\section{Data quality \\ Trustworthiness}

To achieve credibility, the researchers conducted member checks in which informants were asked to comment on the data and on how it was interpreted by the researchers'. ${ }^{18}$ Peer review of coding was conducted by other researchers with experience in the analysis of qualitative data. Confirmability was enhanced by taking detailed field notes and by making field notes available for audit checks and verification by researchers experienced in qualitative data collection and by the taxi industry management. To ensure investigator triangulation, data were obtained by two different investigators. The field notes taken by both investigators during focus group interviews were compared for consistency during analysis.

\section{Data analysis}

The research objectives guided the analysis process. Since only two focus groups were conducted, data were analysed manually, using the content analysis technique. Data from both focus groups were analysed together as a single data set. Data were organized based on the questions, and the researchers then began coding the data under common themes. Issues that recurred in reading through the data were identified as themes, and as the themes emerged they were grouped into categories and subcategories. ${ }^{19}$

\section{Ethical considerations}

The researchers obtained ethics approval from the Uni- 
versity of KwaZulu-Natal Humanities and Social Science Ethics Committee (HSS 0433/08). Permission to undertake the study was obtained from a selected minibus taxi drivers' association in the eThekwini district that controls the activities of the minibus taxi drivers. Participants were provided with information regarding the purpose and background of the study and were informed that participation was voluntary and that they were free to withdraw from participating at any time. Participants were promised that all data collected would remain confidential. To maintain confidentiality, no names or identifying data were collected on the study forms. Pseudonyms were used so that participants could not be identified and the research settings were not specified, thereby protecting the participants. Verbal informed consent was obtained from all respondents prior to their participation in this study.

\section{Results}

The following themes emerged from the data analysis: (i) condom use; (ii) condom negotiation as a source of conflict; (iii) trust issues in the relationship; (iv) shifting responsibilities; and (v) strategies to ensure condom use.

\section{Condom use}

All the taxi queens were asked about the use of condoms in their relationship. The responses were mixed, with some participants using condoms occasionally and others not using condoms at all. What was evident in these responses was that condom use was mainly dependent on the male partner.

We use protection sometimes, but sometimes he does not want it. (Taxi Queen, 5)

We use a condom all the time, but he always complains and says it is uncomfortable. (Taxi Queen, 2)

We don't use a condom since we already have a child. (Taxi Queen, 3)

He does not want the condom, he refuses to use it. Also because I drink, I cannot negotiate condom use. (Taxi Queen, 4)

Our sex life is good sometimes we use condoms if we don't have one in the room we don't. (Taxi Queen, 5)

Not always. Sometimes be does not want to use condoms. (Taxi Queen, 6)

\section{Condom negotiation as a source of conflict}

The taxi queens were aware of the dangers that come with their relationship with the taxi drivers. As such, they recognized that condom use is also part of their responsibilities and they mostly initiated condom use before sex. However, opinions about the use of condoms in sexual intercourse evidently diverged between the taxi queens and the taxi drivers, as the issue frequently seemed to end up in fights and conflicts. Some of the taxi queens recounted the ordeal they usually went through when the issue of condom use was raised before sex:

You see, we do use it but he does not like it and this leads to a big fight (langhing)... we fight big time, that is when we fight. He does not want us to use the condom. (Taxi queen 1)

Eish this happens all the time, you hear me? All the time. We always argue and fight when I insist that we use condom for sex. It never goes well. I have lost count of our fights. (Taxi queen 3) Of course we always have to go through that fight before enjoying sex. But what can one do because they are not trustwortby. (Taxi queen 2)

We fight too much about condoms there never is a time where we don't fight about condoms. (Taxi queen 6)

This led taxi queens to feel that they no longer enjoyed sex with their partners because of the "condom use fight" they had to go through before sexual encounters. Similarly, some taxi drivers felt that it was not easy to negotiate condom use with their queens and even feared losing them if they introduced this topic.

Maybe it's better with married people my sister; they can easily negotiate condom usage with us if you insist on condom usage you can lose the girl. (FGD2).

While it came out strongly in the individual interviews that taxi queens want condom used in sexual activities and that they always initiate it; some of the comments from the taxi driver FGDs presented alternative views. From the minibus taxi drivers it emerged that they expected women take an initiative on condom use but preferred bringing their own condoms. They conceded, however, that they did not always bring their own condoms.

All I can say is that you must be sceptical if a woman is sleeping with you for the first time and refuses to use a condom. FEAR her! It can either be that she wants to fall pregnant or she wants to infect you with the virus, you must run and never come back. (FGD 1).

Ey the problem is that sometimes one is too drunk to even realize that the condom is not on so we rely on them (laughter). (FGD 1). They [women] must also insist that we both use condoms not to just be happy to have sex and not to care whether the condom is on or not. (FGD 2).

They must also protect us and encourage us to use condoms. (FGD 2). 


\section{Trust issues in the relationship}

Since the taxi queens are aware that the taxi drivers are notorious for extra and concurrent sexual relationships it is not surprising that the relationship that exists between taxi queens and taxi drivers is replete with lack of trust. Interestingly however, this does not stop the relationship from beginning. This point was made in comments by taxi drivers in the FGDs:

It even affects our relationship with our spouses. They don't trust us, they become scared of sleeping with us because they are scared of the disease. Yet if they propose the use of a condom in the relationship we don't want to hear anything of it. (FGD 1)

Lack of trust from our girlfriends affects our relationship. Whether you agree to use condom or not, our partners feels we have ulterior motives and that we don't deserve their loyalty. (FGD 2)

One of the taxi queens corroborated the evidence that trust might be missing in a taxi queen-taxi driver relationship when she added that

He is not the person who ever uses a condom, he never uses a condom, something really crossed my mind, I really thought about it....you see, really I was scared, because it might happen that he's intention is to spread the virus...so maybe at some stage I must think about it. (Taxi queen 1)

\section{Shifting responsibilities}

It is interesting to note that both the taxi drivers and the taxi queens expressed expectations as to who should be responsible for the purchase of condoms and initiate their its use. Although participants in the FGD felt that the onus of buying condoms falls on the man "Why should you wait for the woman to ask, you must bring your own [condom]", some of the taxi queens accused the taxi drivers of not being in possession of condoms and of sometimes using the non-availability of condoms as leeway for unprotected sex. One of the taxi queens had this to say about her partner:

He will fight back and then he says if you want to use a condom you must buy it yourself. So what can I do because I am unemployed and cannot always buy condoms. (Taxi queen 4)

However, the taxi queens are sometimes left disappointed because after purchase of a condom, their partners still come up with other excuses

So one day I bought one [condom] and left it here, and said to him let's use a condom, and he asked me when we last had sex did we use a condom or not? And I said no, we didn't use it. So he said why you want to use it today. (He suspected I was seeing someone else) so we ended up having sex without it. (Taxi queen 4)

This suggests that taxi drivers have a variety of ways to avoid use of condom, as borne out by the comments below:
He always complains of tiredness, be wants things to be quick. He is stubborn, short tempered and says the condom wastes his time. We have to get on with it and not delay by using the condom. (Taxi queen 3).

He would say he prefers not to use it because it will bruise him. (Taxi queen 5)

Strategies to ensure condom use

With the taxi drivers having strategies to avoid the use of condoms, as illustrated above, the taxi queens described strategies that they in turn sometimes use to make sure that partners comply with condom use. Taxi queens said that they often/span $>$ resorted to withholding sex to enforce condom use by their partners:

I always win, at the end I always win. Maybe one day be will win but for now, I always win that one. Frankly speak it is a fight if thinking about sex you end up thinking about this condom fight that you have to go through. (Taxi queen 2)

I just refused to have sex with him. I said no condom no sex then, be ended up using it. (Taxi queen 1)

However, the strategy of withholding sex does not always work since either the women end up feeling guilty or the men threaten to withhold benefits of the relationship such as gifts or groceries. Participants in some cases found themselves helpless and powerless in the relationship as their strategies to ensure and enforce consistent use of condoms waned over time: insisting on condom use could be a struggle and was not always successful:

This is the part where I am really struggling because he just won't bear about the condom use. (Taxi queen 3)

There was a time where he flatly refused to use a condom. One day I had sex with him without a condom I had requested that we use a condom and it was bim who refused to use the condom, but we ended up having sex anyway. (Taxi queen 2)

No we don't use it at all, he doesn't like using a condom. He never uses a condom when he has sex, he doesn't use it totally, never ever... so that how the story is. (Taxi queen 4)

\section{Discussion}

Using a qualitative exploratory design, we explored condom use negotiation strategies among taxi drivers and taxi queens in KwaZulu-Natal, South Africa. Our study shed light on participants' experiences in relation to condom use and provided added insight on why this category of population remains one of the most at risk for HIV in South Africa. An increasing public health concern in South Africa is the continually disproportionate impact of HIV on women1 and on young women in particular, among whom HIV prevalence is four times higher than among men. Better understanding of their sexual behaviour is thus a crucial priority. 
This study shows that condom use and negotiation are a source of conflict and put strain on the relationships between taxi drivers and taxi queens. Most of the taxi queens reported that they continuously fight with their partners in trying to insist on condom use. Compliance does not necessarily follow, due to a complex array of factors such as disliking condoms, alcohol usage and unemployment of the female partner which leads to economic dependence on taxi driver boyfriend. The findings of our study are in line with those of other studies showing that men tend to have more negative condom attitudes than women. ${ }^{20,21}$ But whereas concern in previous studies has been related to the loss of pleasure associated with condom use, the reasons cited in our study were related to tiredness and to unaffordability of condoms. Men were more likely to report that condoms reduced sensation for themselves during sex, and women were more likely to report that condoms reduced sensation for their partners.20 Women, in previous studies, understood use of condoms as suggesting lack of trust in their partners. In the current study, in contrast, both men and women already conceded that they were in a multiple-partner relationship and needed to use condoms to protect themselves against HIV. This did not, however, translate to condom use, as men, interestingly, did not trust women who provided them with condoms and women did not trust men who initially did not use a condom in a relationship then suddenly did want to use one.

A degree of relationship inequity was evident in this study with men being the ones who made the decision on condom use. It has been reported that about one in seven HIV infections in South African women are due either to lack of relational power or to male partner violence. ${ }^{21,22}$ Although the focus of our study was not directly related to intimate partner violence or gender inequality, some of the narratives of the female participants nevertheless suggested underlying issues of emotional abuse and poor relational power which could predispose them to HIV infection. Higgins et al.23 debunk the notion that women are the only ones who want to prevent HIV through condom use and that heterosexual men are passive agents in prevention. This notion, according to Higgins et al., ${ }^{23}$ not only disempowers women but also discourages men from actively participating in HIV prevention efforts. Evidence from our FGDs supports the argument by Higgins et al. that men are also sceptical and fearful of women who never ask for condom use during intimacy. This study showed that while taxi drivers acknowledged the importance of condom use, they also shifted the responsibility of purchasing condoms (which was perceived as an additional economic commodity) to their partners, the taxi queens. Although most of the female participants in our study acknowledged that taxi drivers were uncooperative when it comes to condom use, it seems that the taxi queens also put a higher premium on maintenance of the relationship regardless of their agentic position. Several studies ${ }^{15,24,25}$ have acknowledged that even if women possess the agency to negotiate safer sex, they may refrain because they perceive condoms as antithetical to trust, closeness and fidelity. This divergence in opinion on condom use among the study participants suggests that people in heterosexual relationships need to be mutually accountable and empowered (behaviourally, socially and economically) for preventive use of condoms. This is particularly important since the expansion of antiretroviral drugs cannot keep pace with the ever increasing number of people who are getting infected with $\mathrm{HIV}^{25}$

Several studies ${ }^{9,10}$ have reported that the transactional nature of the taxi driver-taxi queen relationships subjects the taxi queens to stigma that undermines their ability to seek help in negotiating safer sexual relationships. However, in our study, there was no incidence of stigma directed at the taxi queens, other than heightened awareness on the part of the taxi queens of increased risk for HIV infection due to their relationship with taxi drivers. The non-reportage of stigma in our study might be due to the focus of our study, which was not directly related to perceptions and attitudes of wider society to the taxi queens' status of being associated with a taxi driver.

\section{Conclusion}

The findings of our study suggest that consistent condom use is the responsibility of both sexes in heterosexual and transactional relationships. Prevention efforts need to focus more on enlightening taxi drivers in regard to safer sex and condom use. Stakeholders should also find ways through which taxi queens can be more empowered for safer negotiation in sexual relationships.

\section{Limitations}

The result of this study should be interpreted with caution due to the small sample size, the homogeneity of the participants, and the similarity in the context of recruitment of the participants. These factors limit the generalizability of the study findings. 


\section{Recommendations}

The findings of the study point to the complex and multidimensional nature of the relationships that exist between taxi drivers and taxi queens. Prevention efforts should accordingly be directed at both the taxi drivers and the taxi queens. Future research should recruit larger numbers of participants, give consideration to their heterogeneity and treat them as dyads.

Factors that militate against condom use should also be given further attention.

\section{Acknowledgements}

South African Medical Research Council for funding the study.

\section{References}

1. Oyediran, K., Odutolu, O, Atobatele A. Intergenerational sexual relationship in Nigeria: Implications for negotiating safe sexual practices. Social and Psychological Aspects of HIV/AIDS and their Ramifications. 2011:49.

2. Masson L, Passmore J-AS, Liebenberg LJ, Werner L, Baxter C, Arnold KB, et al. Genital inflammation and the risk of HIV acquisition in women. Clinical Infectious Diseases. 2015:civ298.

3. Exavery A, Kanté AM, Jackson E, Noronha J, Sikustahili G, Tani K, et al. Role of condom negotiation on condom use among women of reproductive age in three districts in Tanzania. BMC Public Health. 2012;12(1):1097.

4. Mehra D, Östergren P-O, Ekman B, Agardh A. Inconsistent condom use among Ugandan university students from a gender perspective: a cross-sectional study. Global Health Action. 2014;7.

5. Orisatoki R, Oguntibeju O. HIV-related knowledge and condom use by taxi drivers in Southern St. Lucia, West Indies. Scienfific Research and Essays. 2010;5:304-8.

6. Lakew Y, Tamene H. HIV related risk behaviours among taxi drivers and their assistants in Addis Ababa, Ethiopia: descriptive cross-sectional survey. BMC Public Health. 2014;14(1):330.

7. Mchunu G, Ncama B, Naidoo JR, Majeke S, Myeza T, Ndebele T, et al. KwaZulu-Natal minibus taxi drivers' perceptions on HIV and AIDS: Transmission, prevention, support and effects on the industry. SAHARA-J: Journal of Social Aspects of HIV/AIDS. 2012;9(4):210217.

8. Ncama B, Mchunu G, Naidoo J, Majeke S, Pillay P, Myeza T, et al. Minibus taxi drivers' sexual beliefs and practices associated with HIV infection and AIDS in KwaZulu-Natal, South Africa. Curationis. 2013;36(1):16.
9. Strebel A, Shefer T, Potgieter C, Wagner C, Shabalala $\mathrm{N}$. 'She's a slut... and it's wrong': Youth constructions of taxi queens in the Western Cape. South African Journal of Psychology. 2013;43(1):71-80.

10. Potgieter C, Strebel A, Shefer T, Wagner C. Taxi 'sugar daddies' and taxi queens: Male taxi driver attitudes regarding transactional relationships in the Western Cape, South Africa. SAHARA-J: Journal of Social Aspects of HIV/AIDS. 2012;9(4):192-9.

11. Muula AS. HIV infection and AIDS among young women in South Africa. Croatian Medical Journal. 2008;49(3):423.

12. Fladseth K, Gafos M, Newell ML, McGrath N. The impact of gender norms on condom use among HIV-positive adults in KwaZulu-Natal, South Africa. 2015.

13. Gibbs A, Willan S, Potgieter C. Discourses of male condom non-use in South Africa. Poster presented at: XVII International AIDS Conference; 2010, July 18-23; Vienna, Austria.

14. Bantebya G, Ochen E, Pereznieto P, Walker D. Cross-generational and transactional sexual relations in Uganda. 2014.

15. Tschann JM, Flores E, De Groat CL, Deardorff J, Wibbelsman CJ. Condom negotiation strategies and actual condom use among Latino youth. Journal of Adolescent Health. 2010;47(3):254-62.

16. Patton MQ. Two decades of developments in qualitative inquiry a personal, experiential perspective. Qualitative Social Work. 2002;1(3):261-83.

17. Smith JA, Harré R, Van Langenhove L. Rethinking Methods in Psychology: Sage; 1995.

18. Lincoln YS, Guba EG. Establishing trustworthiness. Naturalistic inquiry. 1985;289-331.

19. Strauss AL, Corbin JM. Basics of qualitative research: Sage Newbury Park, CA; 1990.

20. Senn TE, Scott-Sheldon LAJ, Carey MP. Relationship-Specific Condom Attitudes Predict Condom Use among STD Clinic Patients with both Primary and Non-Primary Partners. AIDS Behav. 2014;18(8): 1420 1427.

21. Jewkes RK, Dunkle K, Nduna M, Shai N. Intimate partner violence, relationship power inequity, and incidence of HIV infection in young women in South Africa: a cohort study. The Lancet. 2010;376(9734):41-8.

22. Pronyk PM, Hargreaves JR, Kim JC, Morison LA, Phetla G, Watts C, et al. Effect of a structural intervention for the prevention of intimate-partner violence and HIV in rural South Africa: a cluster randomised trial. The Lancet. 2006;368(9551):1973-83.

23. Higgins JA, Hoffman S, Dworkin SL. Rethinking 
gender, heterosexual men, and women's vulnerabil- 25. Sobo E. Finance, romance, social support, and conity to HIV/AIDS. American Journal of Public Health. dom use among impoverished inner-city women. Hu2010;100(3):435. man Organization. 1995;54(2):115-28.

24. Kline A, Kline E, Oken E. Minority women and 26. Silverman JG. Key to prevent HIV in women: reduce sexual choice in the age of AIDS. Social Science \& Medi- gender-based violence. The Lancet. 2010;376(9734):6-7. cine. 1992;34(4):447-57. 